\title{
RAILONOMICS $^{\circledR}$ - determining investment strategies for railway signalling through simulation
}

\author{
K. Beck, B. Scheier \& B. Jäger \\ Institute of Transportation Systems, German Aerospace Center, \\ Brunswick, Germany
}

\begin{abstract}
The economical effect of an investment strategy in railway signalling is defined by the costs and revenues generated by the chosen system over its lifetime. While the cost positions relevant for an infrastructure manager can all be expressed in the performance figure Life Cycle Costs (LCC), only part of the revenue positions can be expressed monetarily. Therefore, it is necessary to also include non-monetary revenue positions when deciding on which railway signalling system to choose. Since most of the cost and revenue positions are closely linked to the system operation, the idea of using information from railway operation simulation software has been evolved. The Institute of Transportation Systems has therefore implemented a software link between the simulation software RailSys ${ }^{\circledR}$ and a new developed Cost-Benefit-Tool. With the latter the relevant life cycle cost and revenue positions of the evaluated signalling system and scenario can be captured, calculated and analysed. This simulationbased evaluation of investment strategies for railway signalling is part of the RAILONOMICS $^{\circledR}$ concept. RAILONOMICS ${ }^{\circledR}$ enables infrastructure managers to develop efficient investment and maintenance strategies in a structured manner.
\end{abstract}

Keywords: railway signalling, investment strategy, railway operation simulation, decision support system, LCC.

\section{Introduction}

The current situation on the traffic market is characterized by both an increasing traffic demand and a rising level of competition between the traffic modes. To 
benefit from the higher demand and to stand the competition the railway infrastructure managers need to improve their attractiveness for potential customers. This can be achieved primarily by reducing costs and by keeping a high standard in service and quality. Both aspects are strongly determined by the chosen investment strategy. How railway operation simulations in combination with an LCC-Benefit-Tool can be used when determining investment strategies for railway signalling will be presented in this paper. The concept RAILONOMICS ${ }^{\circledR}$ has been developed at the Institute of Transportation Systems to address different economical aspects in the railway domain with the aim to achieve a lasting economical success. The use of and the results achieved with the developed concept are illustrated on two secondary railway lines taken as an example from the German railway network.

\section{Economic efficiency of investment strategies}

Investments in railway signalling have a long lasting influence on the economical success of railway infrastructure companies. This is due to their long lifetimes of at least 25 years. During this period the signalling infrastructure contributes to the revenues generated through the sale of rail lines to operator companies as well as to the costs which are caused by the operation and maintenance of the system. Extensive considerations of pros and cons of different signalling systems are therefore indispensable when making investment decisions. While the pros of the signalling system express the benefit aspects, the cons can be subsumed in the figure Life Cycle Costs (LCC). The relationship between the system benefit and costs can then be expressed in the performance figure Net Present Value (NPV) of the investment over the regarded period of approximately 25 years. The economic efficiency of an investment strategy is the better the higher the NPV is. The mathematical expression for the NPV shows eqn (1). The revenues (R) and costs (C) per year and the chosen interest rate (q) over the regarded time period (n) are the input variables.

$$
\mathrm{C}_{\mathrm{o}}=\sum_{\mathrm{t}=0}^{\mathrm{n}}\left(\mathrm{R}_{\mathrm{t}}-\mathrm{C}_{\mathrm{t}}\right) \times \frac{1}{\mathrm{q}^{\mathrm{t}}} \text {. }
$$

Therefore, when deciding on which investment strategy in railway signalling to choose, the LCC as well as the benefit factors need to be identified and evaluated. Corresponding to Zangemeister [1] investment decisions should not only be based on monetary figures. Qualitative benefit aspects, that are aspects which cannot be expressed in monetary units, also need to be considered. The general terms relevant for economic efficiency evaluations for railway signalling will be explained.

\subsection{Life cycle costs}

Life Cycle Costs are defined as the sum over all costs generated throughout the life cycle phases as shown in figure 1 [2]. As investment decisions only regard the system procurement, its service and disposal (market cycle) the processes of 
system definition, development and project planning (formation cycle) and the costs generated within this period are not relevant at this point.

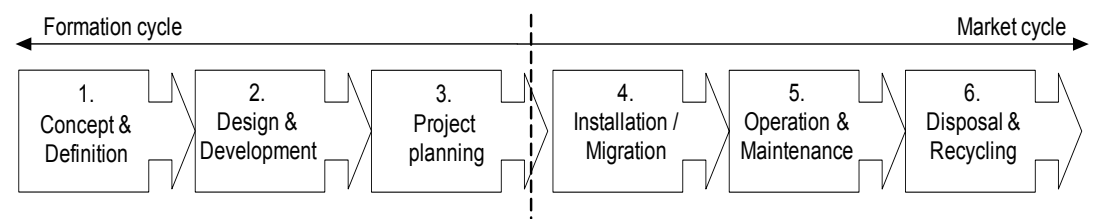

Figure 1: $\quad$ Product life cycle phases.

For the evaluation of different investment strategies in railway signalling the following life cycle costs need to be considered:

- Procurement expenses including installation costs

- Planning costs

- Deconstruction costs (if track is already equipped)

- Costs of capital/ opportunity costs

- Operation costs

- Preventive and corrective maintenance costs

Disposal costs which are partly considered in the deconstruction costs will not be regarded in detail because of the long life times of the components and therefore the low effect of this cost position on the LCC (cp. eqn (1)).

All LCC aspects have to be determined for the infrastructure elements which are required for the regarded investment strategy. Therefore each investment strategy has to be defined by the needed infrastructure. For economic efficiency evaluations these information can be gathered from railway operation simulations. In addition there is static information needed which as well determines the LCC. This is for example the purchase price for a main signal or its maintenance frequency and duration. They are called static since they are independent from the actual investment strategy evaluated. These figures need to be recorded in the LCC-Benefit-Tool.

\subsection{Benefit evaluation}

As mentioned before when doing a benefit evaluation a distinction between monetary and non-monetary benefit aspects is necessary. On the one hand the railway signalling significantly contributes to the sale of rail lines to train operator companies. This benefit aspect can easily be expressed monetarily as a revenue position in equation (1). On the other hand the railway signalling system contributes a lot to 'soft' indicators as safety, operation flexibility etc. [2]. These aspects cannot and should not be expressed in monetary units. Instead they should be evaluated separately. Which benefit criteria are of importance for evaluating railway signalling investment strategies is shown in table 1 . Note that the table does make no claim to be complete because it is in the eye of the beholder which criteria are relevant.

When doing qualitative benefit evaluations it is important to keep the influence of the decision maker at a low level with the use of standardized 
methods. Nevertheless qualitative evaluations are always more subjective than quantitative ones. But even than it is better evaluating qualitatively than trying to express each benefit criteria monetarily [1].

Table 1: $\quad$ Benefit criteria.

\begin{tabular}{|l|l|}
\hline \multicolumn{1}{|c|}{ Criterion } & \multicolumn{1}{c|}{ Definition / Comment } \\
\hline \hline Access for trains & $\begin{array}{l}\text { Ability of the operation procedure to offer track access } \\
\text { for trains which are not refitted }\end{array}$ \\
\hline $\begin{array}{l}\text { Alternative use of the system of } \\
\text { continuous supervision of trains }\end{array}$ & e.g. use for passenger information systems \\
\hline Capacity surplus & $\begin{array}{l}\text { The amount of free capacity after fulfilling the } \\
\text { demanded timetable }\end{array}$ \\
\hline $\begin{array}{l}\text { Complexity for shunting } \\
\text { operations }\end{array}$ & $\begin{array}{l}\text { Influence of the operation procedure to build and release } \\
\text { shunting routes (e.g. time) }\end{array}$ \\
\hline $\begin{array}{l}\text { Constructional flexibility for } \\
\text { structuring train stations }\end{array}$ & $\begin{array}{l}\text { Flexibility when planning number of tracks, switches, } \\
\text { signals, etc. }\end{array}$ \\
\hline Delay reduction & $\begin{array}{l}\text { Defined by the sum of delay minutes; the fewer the } \\
\text { merrier }\end{array}$ \\
\hline $\begin{array}{l}\text { Flexibility for constructional } \\
\text { changes in existing system }\end{array}$ & $\begin{array}{l}\text { The ability to perform constructional changes at a train } \\
\text { station, e.g. the number of lines after system is installed }\end{array}$ \\
\hline $\begin{array}{l}\text { Flexible disturbance } \\
\text { management }\end{array}$ & $\begin{array}{l}\text { The efficiency to handle and clear an infrastructure } \\
\text { disturbance }\end{array}$ \\
\hline $\begin{array}{l}\text { Flexible scheduling } \\
\text { management }\end{array}$ & $\begin{array}{l}\text { The ability of the signalling system and its operation } \\
\text { procedure to perform an efficient scheduling }\end{array}$ \\
\hline Gateway & The crossover from one operation procedure to the next \\
\hline Maximum speed & $\begin{array}{l}\text { The maximum allowable track speed of the chosen } \\
\text { system }\end{array}$ \\
\hline $\begin{array}{l}\text { Migration of the operation } \\
\text { procedure }\end{array}$ & $\begin{array}{l}\text { The migration of the operation procedure and the trains } \\
\text { if one is existent before }\end{array}$ \\
\hline and train overtaking & $\begin{array}{l}\text { This criterion is important for unscheduled trains and } \\
\text { the ability of the operation procedure to be flexible in } \\
\text { changing the timetable afterwards (raise the number of } \\
\text { trains) }\end{array}$ \\
\hline Safety & $\begin{array}{l}\text { Type of train protection, type of clear track signalling } \\
\text { system, etc. }\end{array}$ \\
\hline
\end{tabular}

Part of the benefit criteria as listed above can be measured through the results from the railway simulation. They are quantitative but non-monetary figures. Others are pure qualitative aspects and have to be evaluated based on the knowledge of experts. Besides that, the relevant benefit criteria also need to be weighted against each other.

Before making decisions on which investment strategy in railway signalling to choose the results from the LCC- and the benefit evaluations have to be merged and illustrated. Result illustrations can best be made by the use of portfolio diagrams. In the following the procedure of how to use railway operation simulations as a basis for deciding on investment strategies in the railway domain and which results can be obtained will be illustrated. 


\section{Simulative evaluations}

The investment strategies in railway signalling are determined by the chosen program of operation. Therefore the decision maker needs to figure out which operation procedures are possible and reasonable for the rail track or net to evaluate. After this the identified rail operation procedures are modelled in the simulation software and simulated afterwards. The results received through the output files are the fundament for the economic efficiency evaluation and for the final investment decision.

\subsection{Object of investigation}

The potentials of using both, rail simulation software and the Cost-Benefit-Tool, will be illustrated on two linked secondary railway lines. The chosen track section, which currently is equipped with mechanical and electromechanical interlocking, has the following features:

- Single way track

- Fix timetable with approximately one train per hour and direction

- Minimum speed of $80 \mathrm{~km} / \mathrm{h}$

There have been no changes in the infrastructure itself (number of lines, block intervals etc.). In addition the given timetable as well as the minimum speed are must-haves and therefore need to be fulfilled by the signalling system. Regarding these restrictions the following 4 railway operation procedures and the needed signalling infrastructure (cp. table 2) have first been identified [4] and then simulated and evaluated by the use of the railway operation simulation software RailSys ${ }^{\circledR}$ and the Cost-Benefit-Tool.

Table 2: $\quad$ Operation procedures.

\begin{tabular}{|c|c|c|c|c|c|c|}
\hline \multirow{2}{*}{\multicolumn{2}{|c|}{\begin{tabular}{|l|} 
Operating procedure \\
Infrastructure element \\
\end{tabular}}} & \multirow[t]{2}{*}{$\begin{array}{l}\text { telephone block- } \\
\text { Mechanical Interlocking }\end{array}$} & \multirow[t]{2}{*}{$\begin{array}{l}\text { telephone block - } \\
\text { Electronic interlocking }\end{array}$} & \multirow[t]{2}{*}{$\begin{array}{l}\text { train dispatcher with } \\
\text { electronic interlocking }\end{array}$} & \multicolumn{2}{|c|}{$\begin{array}{c}\text { train dispatcher - no technical } \\
\text { support }\end{array}$} \\
\hline & & & & & & \\
\hline Switches & \begin{tabular}{c|}
$\#$ \\
Type
\end{tabular} & $\begin{array}{l}63 \\
\text { mechanical-operated } \\
\text { switch }\end{array}$ & $\begin{array}{l}\frac{63}{1} \\
\text { remote-controlled } \\
\text { switch }\end{array}$ & $\begin{array}{l}63 \\
\text { remote-controlled } \\
\text { switch }\end{array}$ & \begin{tabular}{l}
\multicolumn{1}{c}{40} \\
hand-operated \\
switch
\end{tabular} & $\begin{array}{l}\text { trailable one } \\
\text { way switch }\end{array}$ \\
\hline Caution signal & \# & 36 & 36 & 36 & & 0 \\
\hline Main signal & \# & 85 & 85 & 85 & & 0 \\
\hline Track circuit & \# & 85 & 0 & 0 & & 0 \\
\hline Axle counter & $\#$ & 0 & 85 & 85 & & 0 \\
\hline Track magnet & \# & 206 & 206 & 206 & & 0 \\
\hline Stop board & $\#$ & 33 & 33 & 33 & & 53 \\
\hline Trapeze board & $\#$ & 0 & 0 & 0 & & 23 \\
\hline $\begin{array}{l}\text { Mechanical } \\
\text { interlocking }\end{array}$ & $\#$ & 14 & 0 & 0 & & 0 \\
\hline $\begin{array}{l}\text { Electromechanical } \\
\text { interlocking }\end{array}$ & $\#$ & 2 & 0 & 0 & & 0 \\
\hline $\begin{array}{l}\text { Electronic } \\
\text { interlocking }\end{array}$ & $\#$ & 0 & 1 & 0 & & 0 \\
\hline $\begin{array}{l}\text { Electronic } \\
\text { interlocking - branch }\end{array}$ & \# & 0 & 10 & 0 & & 0 \\
\hline Train dispatcher & \# & 0 & 0 & 2 & & 4 \\
\hline Local workstation & \# & 0 & 0 & 9 & & 0 \\
\hline
\end{tabular}

\subsection{LCC evaluation}

Aim of the LCC evaluation is to determine the costs caused by the identified operation procedures over a defined period of time. 25 years of operation is a 
realistic life time for the regarded signalling equipment and has therefore been implemented in the LCC-Benefit-Tool. All LCC aspects as listed in 2.1 apart from the downtime costs have been considered. Especially the number and kind of infrastructure elements as well as the operation times retrieved from the railway simulation are important for the LCC evaluation. The static information needed is similar to the numbers used by the German Railways (i.e. maintenance intervals, planning cost as a percentage of the procurement expenses, etc.).

Figure 2 shows the LCC for the processes between which has been distinguished - investment and planning, deconstruction, operation (not including downtime costs) and maintenance. Costs for operation and maintenance are only shown on a one-year basis since they are assumed to be the same each year over the regarded period of 25 years. This implies that possible changes regarding the timetable or the maintenance frequencies over a time period of 25 years have not been taken into account. Figure 2 clearly indicates the life cycle processes which are most cost intensive. When installing electronic interlocking the procurement expenses are high. These expenses can be justified through lower operation costs compared to the scenario in which mechanical and electromechanical interlocking have been simulated.

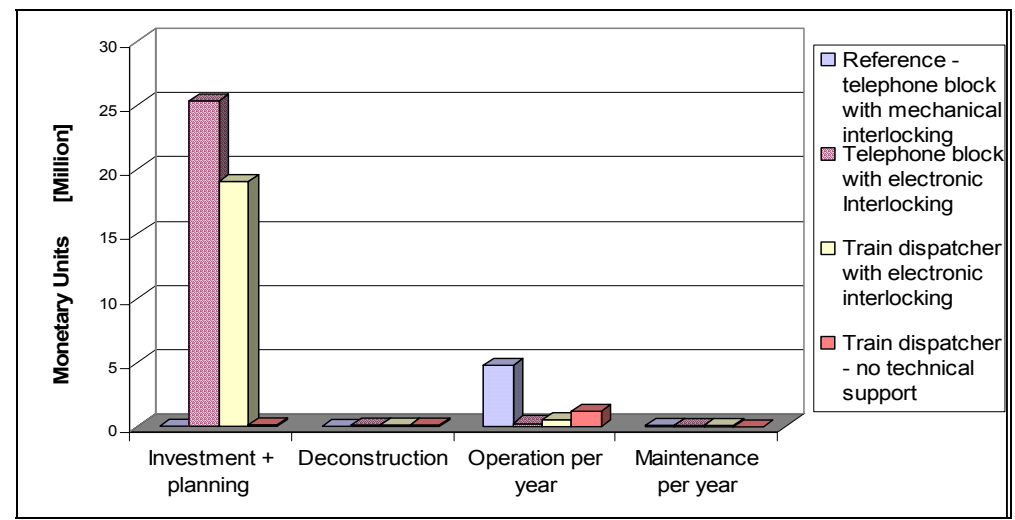

Figure 2: $\quad$ LCC per life cycle process.

That cost savings can be realized when changing from the currently implemented use of mechanical interlockings to another operation procedure with the use of different signalling equipment indicates figure 3 . Even though for the reference scenario neither investment expenses nor deconstruction costs are generated since the tracks are already equipped, the use of electronic interlockings is economically more efficient after a period of 8.5 years (train dispatcher) and respectively 11 years (telephone block). This is when the breakeven point is reached. This effect is only due to the immense operation costs caused by a high number of staff needed when using mechanical interlockings. Compared to the current situation the implementation of train dispatchers without technical support and one way switches is least cost-effective over the regarded time period of 25 years. This is a consequence of the fact that for 
running this operation procedure almost no signalling equipment is needed (cp. table 2) and therefore low investment expenses and maintenance costs are caused.

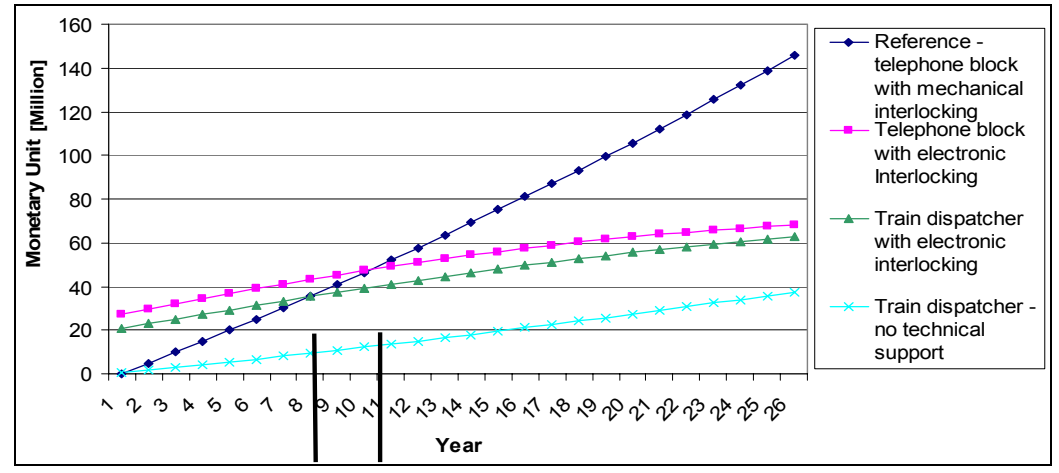

Figure 3: $\quad$ LCC for each investment scenario in 25 years.

But of course there are differences in performance between the regarded investment decisions. Since most of the performance figures cannot be expressed monetarily and to avoid making such important, since long lasting, investment decisions only based on the LCC, a detailed benefit evaluation of each investment scenario is necessary.

\subsection{Benefit evaluation}

The benefit evaluation summarizes the results of a detailed performance analysis and allows a more profound information basis for making the investment decision. Since all 4 scenarios fulfil the current timetable, the number of sold train tracks and therefore the monetary benefit is the same and does not have to be analysed in the benefit evaluation. For the qualitative benefit evaluation only the criteria of the ones mentioned in table 1 which are relevant for the object of investigation have been evaluated. The non-monetary benefit evaluation has been conducted based on the following criteria:

- Safety

- Flexible scheduling management

- Maximum speed

- Alternative use of the system of continuous supervision of trains

- Possibility for train crossings and train overhauling

- Delay Reduction

- Flexibility for constructional changes

- Flexible disturbance management

- Capacity Surplus

With the use of the results from the railway simulation and expert knowledge the following results have been achieved for the qualitative benefit evaluation (see table 3) whereas the benefit value 9 indicates that the criterion is best 
fulfilled, 1 that the criterion is not fulfilled or is least fulfilled. All figures have been determined for the regarded track section and topology and do not give a general statement about the evaluated operation procedures.

Table 3: Non-monetary benefit evaluation.

\begin{tabular}{|c|c|c|c|c|c|}
\hline Criterion & Weighting & \begin{tabular}{|l} 
Reference - telephone \\
block with mechanical \\
interlocking
\end{tabular} & \begin{tabular}{|l|}
$\begin{array}{l}\text { Telephone block } \\
\text { with electronic } \\
\text { Interlocking }\end{array}$ \\
\end{tabular} & $\begin{array}{l}\text { Train dispatcher } \\
\text { with electronic } \\
\text { interlocking } \\
\end{array}$ & $\begin{array}{l}\text { Train dispatcher } \\
\text { no technical } \\
\text { support }\end{array}$ \\
\hline Safety & 0,22 & 9 & 9 & 9 & 1 \\
\hline $\begin{array}{c}\text { Flexible scheduling } \\
\text { management }\end{array}$ & 0,13 & 1 & 9 & 7 & 3 \\
\hline Maximum speed & 0,10 & 9 & 9 & 6 & 1 \\
\hline $\begin{array}{l}\text { Alternative use of the system for } \\
\text { continuous supervision of trains }\end{array}$ & 0,03 & 1 & 9 & 9 & 1 \\
\hline $\begin{array}{c}\text { Possibility for train crossings and } \\
\text { train overtaking } \\
\end{array}$ & 0,10 & 9 & 9 & 9 & 1 \\
\hline Delay reduction & 0,14 & 2 & 9 & 5 & 1 \\
\hline $\begin{array}{l}\text { Flexibility for constructional } \\
\text { changes }\end{array}$ & 0,06 & 8 & 5 & 9 & 3 \\
\hline $\begin{array}{c}\text { Flexible disturbance } \\
\text { management }\end{array}$ & 0,15 & 9 & 4 & 6 & 6 \\
\hline Capacity surplus & 0,08 & 9 & 9 & 1 & 1 \\
\hline Total & 1,00 & 6,74 & 8,01 & 6,77 & 2,13 \\
\hline
\end{tabular}

The considerations made for determining the benefit values for each scenario and benefit criteria as indicated in table 3 shall be shortly outlined in the following.

Safety - Because of the absence of an automatic train protection system the operation procedure "train dispatcher - no technical support" is evaluated as low as possible.

Flexible scheduling management - Since no computer-aided scheduling is available in the operation procedures "telephone block with mechanical interlocking" and "train dispatcher - no technical support" both procedures get less benefit values. In addition there are more movement inspectors involved in the procedure "telephone block with mechanical interlocking" than in the other three procedures. In procedure "Train dispatcher with electronic interlocking" the communication has to be done by 2 movement inspectors instead of 1 in "Telephone block with electronic interlocking".

Maximum speed - "Telephone block with mechanical interlocking" and "Telephone block with electronic interlocking" allow a maximum speed of 160 $\mathrm{km} / \mathrm{h}$; "Train dispatcher with electronic interlocking" enables the train to run at a speed of up to $120 \mathrm{~km} / \mathrm{h}$; "Train dispatcher - no technical support" only offers a maximum speed of $80 \mathrm{~km} / \mathrm{h}$ which corresponds to the minimum required speed.

Alternative use of the system for continuous supervision of trains - The system for continuous supervision of trains is not existent in the operation procedures "train dispatcher - no technical support" and "telephone block with mechanical interlocking".

Possibility for train crossings and train overhauling - Because of the utilization of trailable one way switches train overhauling is more difficult to realise in the operation procedure "train dispatcher - no technical support". 
Delay reduction - The given benefit points are due to the result out of 20 multi-simulated disturbed timetables. The procedure with the most delay minutes got 1 benefit point, the one with the least got 9 points.

Flexibility for constructional changes - The software used in the electronic interlocking in procedure "telephone block with electronic interlocking" is complicated and complex, changes are difficult to realise. This is easier in "train dispatcher with electronic interlocking" because the installed software is less complex. In operation procedure "train dispatcher - no technical support" constructional changes of a train station are not possible without the use of a local interlocking and additional staff.

Flexible disturbance management - With the operation procedure "telephone block with mechanical interlocking" the handling of disturbances is easier because of more staff available for the process. With "train dispatcher with electronic interlocking" operation messages can be send just as in operation procedure "train dispatcher - no technical support". In comparison, in case of disturbance in operation procedure "telephone block with electronic interlocking" running at sight might be the only possible way.

Capacity surplus - The operation procedures which use train dispatchers are currently at the capacity limit because of a maximum possible work load for each installed train dispatcher which is already achieved. For additional capacity more train dispatchers are needed which at this point are not part of the evaluation.

\subsection{Economic efficiency statement}

A portfolio diagram summarizes the results of both evaluation steps. The results achieved during the presented investigation shows figure 4 .

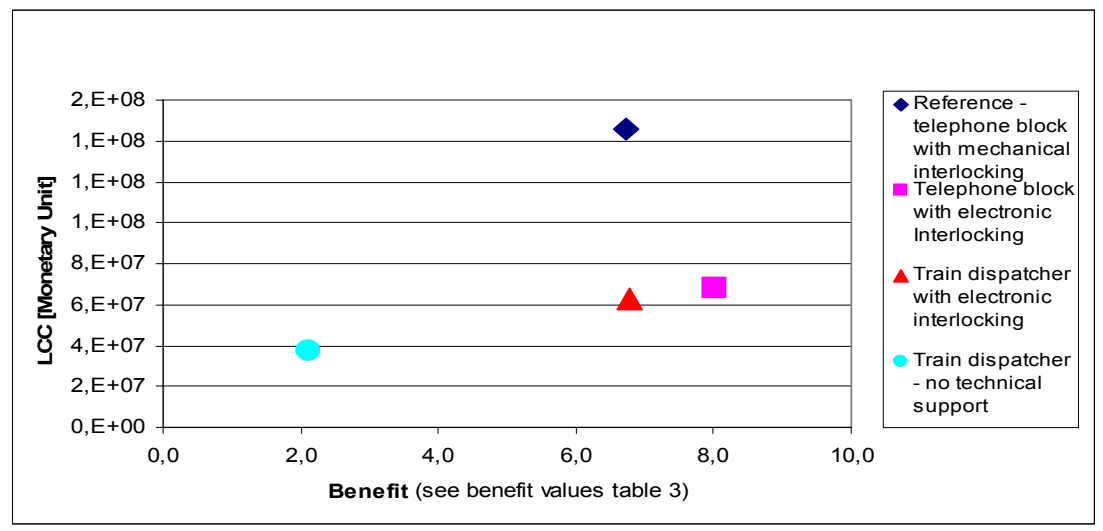

Figure 4: $\quad$ LCC-benefit-portfolio.

As indicated the use of an electronic interlocking either in the way of a telephone block or a train dispatcher system achieves similar results, the latter scenario is a little less cost intensive but also achieves a lower benefit value. The present situation with the use of mechanical interlockings is the most cost 
intensive over the regarded period of 25 years, but achieves a lower benefit value compared to the use of electronic interlockings. The operation procedure without the use of technical support achieves both, the least cost as well as the least benefit.

The final decision on which investment strategy to choose depends on the preferences of the company and its decision makers, their scope of decisionmaking and which aspects are more relevant - LCC or benefit.

\section{Conclusions and perspectives}

The methodical approach described in this paper allows systematic evaluations for making profound investment decisions in railway signalling as it becomes more necessary in a competitive environment. The exemplary evaluation shows that the use of old, personnel-intensive signalling equipment is highly costinefficient, even when considering high procurement and deconstruction expenses needed for installing new equipment. In addition the high LCC number cannot be accepted by looking at the benefit side since this is lower than the ones achieved with the use of electronic interlockings. But it became also clear that the results presented in figure 4 are dependent on the decision-makers and the investment environment and should therefore not been seen as hard and fast.

As a perspective the institute is aiming for an advancement of the LCCBenefit-Tool and its link to railway operation simulation software. The link will be created interoperable to most of the simulation software. This extends the capabilities of the LCC-Benefit-Tool. Further studies will also consider different infrastructure scenarios and timetables and their effect on the economic efficiency of the evaluated railway track or net. Both aspects can be addressed with the tool link as part of the RAILONOMICS ${ }^{\circledR}$ concept. This will be done just as comfortable as the shown evaluation of railway signalling investment strategies.

\section{References}

[1] Zangemeister, C., Erweiterte Wirtschaftlichkeits-Analyse (EWA) Grundlagen und Leitfaden für ein "3-Stufen-Verfahren" zur Arbeitssystembewertung, Dortmund 1993

[2] DIN EN 60300-3-3 Dependability management - Part 3-3: Application guide - Life cycle costing (IEC 60300-3-3:2004). German version

[3] Naumann, P., Pachl, J., Leit- und Sicherungstechnik im Bahnbetrieb, Fachlexikon, Band 2, Hamburg 2004

[4] Verband Deutscher Verkehrsunternehmen (VDV), VDV Schriften 752 08/00 - Empfehlungen zur Auswahl geeigneter Betriebsverfahren für eingleisige Eisenbahnstrecken, Köln 2000 